\title{
Participation in cervical screening by Indigenous women in the Northern Territory: a longitudinal study
}

\author{
Philippa L Binns and John R Condon
}

T he incidence of cervical cancer and mortality from the disease have been declining in Australia for many years. National rates are now among the lowest for developed countries. ${ }^{1,2}$ These reductions are attributed largely to the successful implementation of the National Cervical Screening Program. ${ }^{1,3}$ Reductions have also occurred more recently in Indigenous women in the Northern Territory, but both incidence and mortality in these women remain considerably higher than national levels: between 1991 and 2001, the incidence of cervical cancer in NT Indigenous women was 2.6 times - and mortality 8.6 times - that of all Australian women., ${ }^{4,5}$

Indigenous residents comprise $29 \%$ of the NT population, two-thirds of whom live in rural and remote areas. ${ }^{6}$ As part of the national program, the NT Women's Cancer Prevention Program (NTWCPP) established the Remote Areas Well Women's Screening Program in $1994,^{7}$ and the NT Pap Smear Register (NTPSR) in 1996, to provide cervical screening support and screening reminders for women and providers. The NTPSR has reported screening participation rates for the entire NT population, ${ }^{8}$ but not for Indigenous and non-Indigenous women separately, as it does not record Indigenous status.

We hypothesised that the decline in cervical cancer incidence and mortality in NT Indigenous women was associated with increased participation in cervical screening. We examined regional screening participation rates and trends between 1997 and 2004 for all NT women, and, using an indirect estimate, for Indigenous women living in rural and remote areas where the population is predominantly Indigenous.

\section{METHODS}

This was a retrospective study that used data from NTPSR records for the period January 1997 to December 2004. The study population comprised women aged 20-69 years who had a Pap smear during the study period and had an NT address recorded on the NTPSR. Data on Pap smears and women's age and place of residence were

\section{ABSTRACT}

Objective: To investigate the effectiveness of the Northern Territory Women's Cancer Prevention Program in improving cervical screening participation for Indigenous women.

Design: Descriptive longitudinal period prevalence study.

Participants: All NT resident women aged 20-69 years who had at least one Pap smear recorded on the NT Pap Smear Register between 1997 and 2004.

Main outcome measures: Indirectly estimated percentage of NT Indigenous women in rural and remote areas with a predominantly Indigenous population (accounting for $55 \%$ of the NT Indigenous population) who participated in screening, in biennial periods between 1997 and 2004. Participation by all eligible NT women (both Indigenous and non-Indigenous) is also reported by region for the same period.

Results: In 1997-1998, estimated participation for Indigenous women was about half the national rate $(33.9 \%$ [95\% Cl, 32.6\%-35.2\%] v $63.9 \%$ [95\% Cl, 63.8\%-63.9\%]).

Participation increased to $44.0 \%(95 \% \mathrm{Cl}, 42.7 \%-45.4 \%)$ in $1999-2000$, and changed little thereafter; participation was higher in the Top End compared with Central Australia, and varied from $16.6 \%$ to $75.0 \%$ between remote areas. Participation rates for all women living in rural/remote regions were lower than those in urban regions.

Conclusions: Recruitment of Indigenous women for cervical screening has improved since 1999. This may have partly contributed to the fall in their cervical cancer incidence and mortality in recent years. Although in most areas Indigenous participation is lower than national levels, in one area it was considerably higher. Improvements can be achieved by learning from these communities, to further close the gap in morbidity and mortality between Indigenous and non-Indigenous women.

MJA 2006; 185: 490-494

For editorial comment, see page 476 . See also page 482

obtained from the NTPSR, which includes Pap smear results for women who do not "opt off" the register.

\section{Regional participation rates (all NT women)}

Participation rates for NT women (Indigenous and non-Indigenous combined) were calculated for four biennial periods between 1997 and 2004 for the seven Aboriginal and Torres Strait Islander Commission (ATSIC) regions in the NT. These comprise two urban regions (Alice Springs and Darwin) and five rural/remote regions (Box 1). We used ATSIC regions, which closely approximate NT Government Administrative Health Districts, because estimated resident populations were available from the Australian Bureau of Statistics (ABS) for the ATSIC regions but not for the health districts.

Previously, the NTPSR allocated women to administrative health districts on the basis of their postal address postcode. However, mail to some border communities in South Aus- tralia and Western Australia is delivered via the NT, and, consequently, women in these communities were incorrectly coded as NT residents (eg, Ernabella, SA, has the postal address "via Alice Springs PO Bags, NT 0872"). In our study, we allocated regions of residence using information from all address fields (not just postcode) in the NTPSR database. As a result, about a quarter of women previously coded as residents of the Alice Springs Rural Administrative Health District (equivalent to the Apatula region shown in Box 1) were excluded from our study as residents of other states. This reallocation also corrected previous regional misclassifications of women within the NT.

Consistent with national performance indicators, the rate of participation in cervical screening was calculated as the proportion of women in the target population who had at least one Pap smear in each 2-year period. We divided the number of women aged 20-69 years who had at least one smear in a 2-year period by the number of eligible women in the same time period 


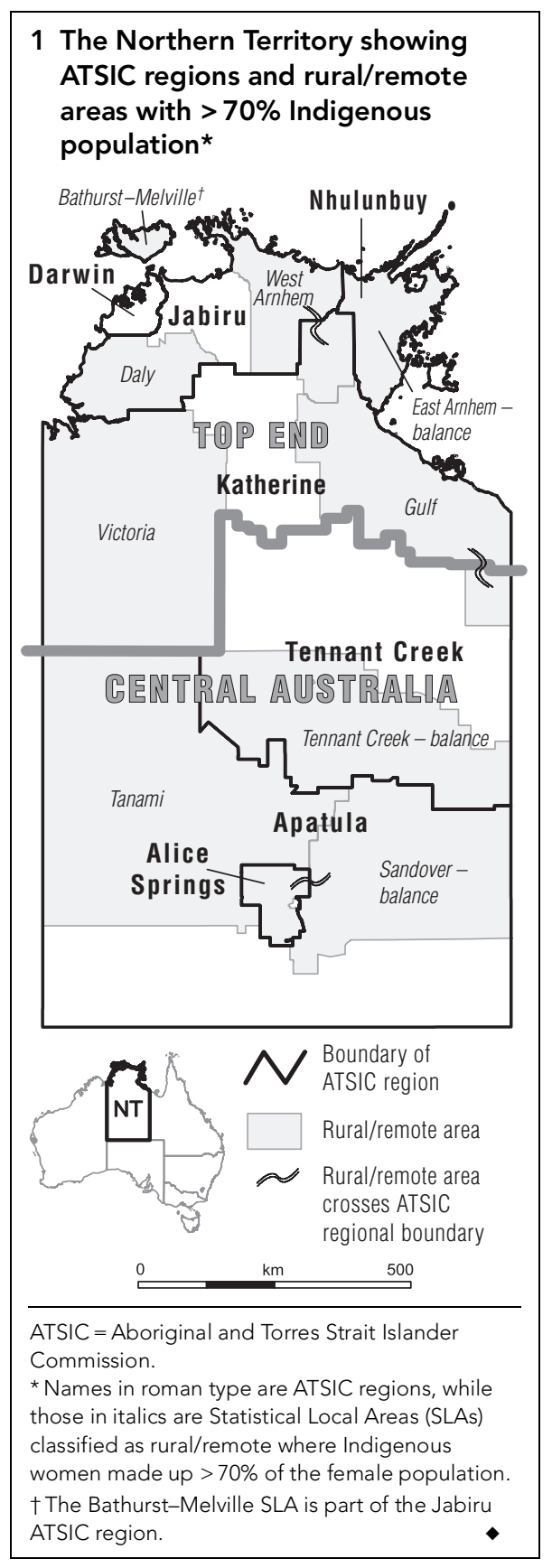

(estimated as the mean of the two annual ABS population estimates for the period).

\section{Estimated Indigenous participation rates}

Although the NTPSR is permitted by NT Public Health Regulations to include data on Indigenous status, it does not do so, as these data are not recorded by federally funded pathology services. ${ }^{9}$ Therefore, we could not directly calculate Indigenous participation rates in cervical screening. Instead, we estimated rates indirectly for the nine rural/remote areas in which

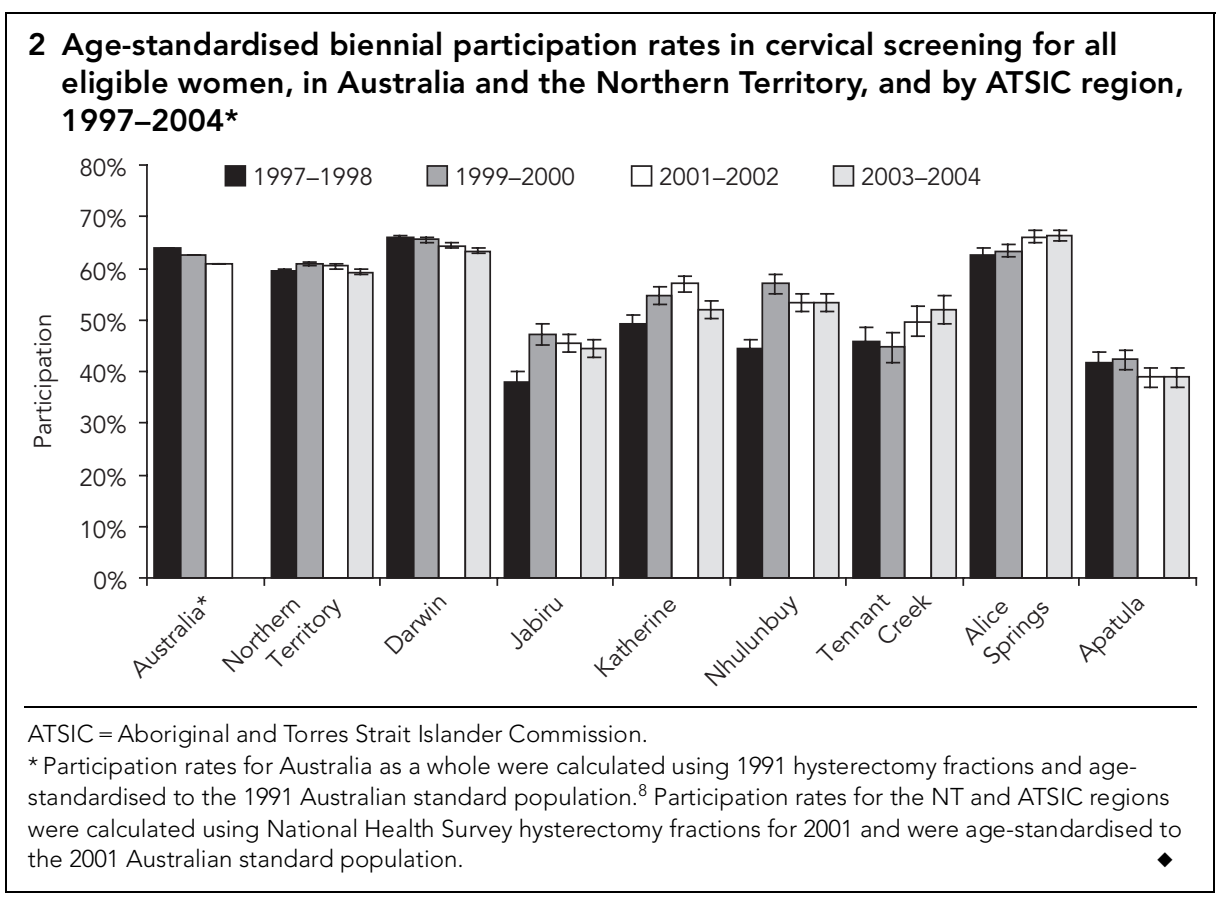

Indigenous women comprised $70 \%$ or more of the total female population (Box 1 ). We chose these areas because indirect estimates would have been less accurate for populations with lower proportions of Indigenous women. These nine areas encompass $55 \%$ of the NT female Indigenous population.

As with regional participation, area of residence was allocated using information from all address fields in the NTPSR database. We used Statistical Local Areas (part of the Australian Geographic Classification System ${ }^{10}$ ) to define rural/remote area boundaries, as Indigenous and non-Indigenous population estimates were available for these areas for the year 2001 from the ABS. We derived population estimates for other years by assuming that the rate of population change (within 5-year age groups, separately for Indigenous and non-Indigenous populations) was the same for each area as for the corresponding ATSIC region.

We calculated participation rates for Indigenous women in these areas, assuming that rates for non-Indigenous women were equivalent to those for the Australian population (ie, 61\% in 2001). Thus, the number of Indigenous women having smears in each area in each biennial period was estimated by subtracting $61 \%$ of the eligible non-Indigenous women from the number of eligible women who had at least one smear. This result was divided by the mean of the two mid-year estimates of the eligible Indigenous population to give an indirect estimate of Indigenous participation rates.

We performed sensitivity analyses by varying the assumption of a $61 \%$ non-Indigenous participation rate by $10 \%$ (ie, $51 \%$ and $71 \%$ participation). The effect of the different assumptions was examined using absolute rate differences.

\section{Statistical analyses and ethics approval}

All participation rates were age-adjusted to the 2001 Australian population age distribution, ${ }^{11}$ and all population figures were adjusted to remove the proportion of women estimated to have undergone a hysterectomy (based on the 2001 National Health Survey hysterectomy fractions ${ }^{12}$ ). Results were compared with total NT and Australian rates obtained from national reports ${ }^{8}$ over the corresponding time periods.

Tests for trend were not performed, as trend assessment is difficult when there are four or fewer data points, and as there appeared to be more than one trend within the 8-year period for many of the comparisons (eg, a large increase during one period followed by a gradual decline thereafter).

Stata 8.0 statistical software (StataCorp, College Station, Tex, USA) was used for statistical analysis.

Our study was approved by the Human Research Ethics Committee of the NT Department of Health and Community Services and the Menzies School of Health Research. 


\section{RESULTS}

\section{Regional participation for all} NT women

Participation rates in NT urban regions were higher than national rates from at least 1997 onwards in Darwin, and from 2000 in Alice Springs (Box 2). Rates in all rural/remote regions were lower than Australian rates. The three Top End rural/ remote regions (Jabiru, Katherine and Nhulunbuy) showed improvements in participation rates between 1997-1998 and 1999-2000, with no overlapping confidence intervals. These improvements were maintained above the 1997-1998 baseline despite a downward trend in subsequent years. Since 1999-2000, the Apatula region in Central Australia has consistently had the lowest rates.

\section{Indigenous participation}

In 1997-1998, the overall estimated participation rate for Indigenous women living in the "> 70\% Indigenous areas" was about half the Australian rate (33.9\% [95\% CI, 32.6\%-35.2\%] versus 63.9\% [95\% CI, $63.8 \%-63.9 \%]$ ). In 1999-2000, the rate for Indigenous women increased to $44.0 \%$ (95\% CI, 42.7\%-45.4\%). There was little change from 1999-2000 to 2003-2004, with Indigenous participation rates remaining 18-19 percentage points lower than Australian rates.

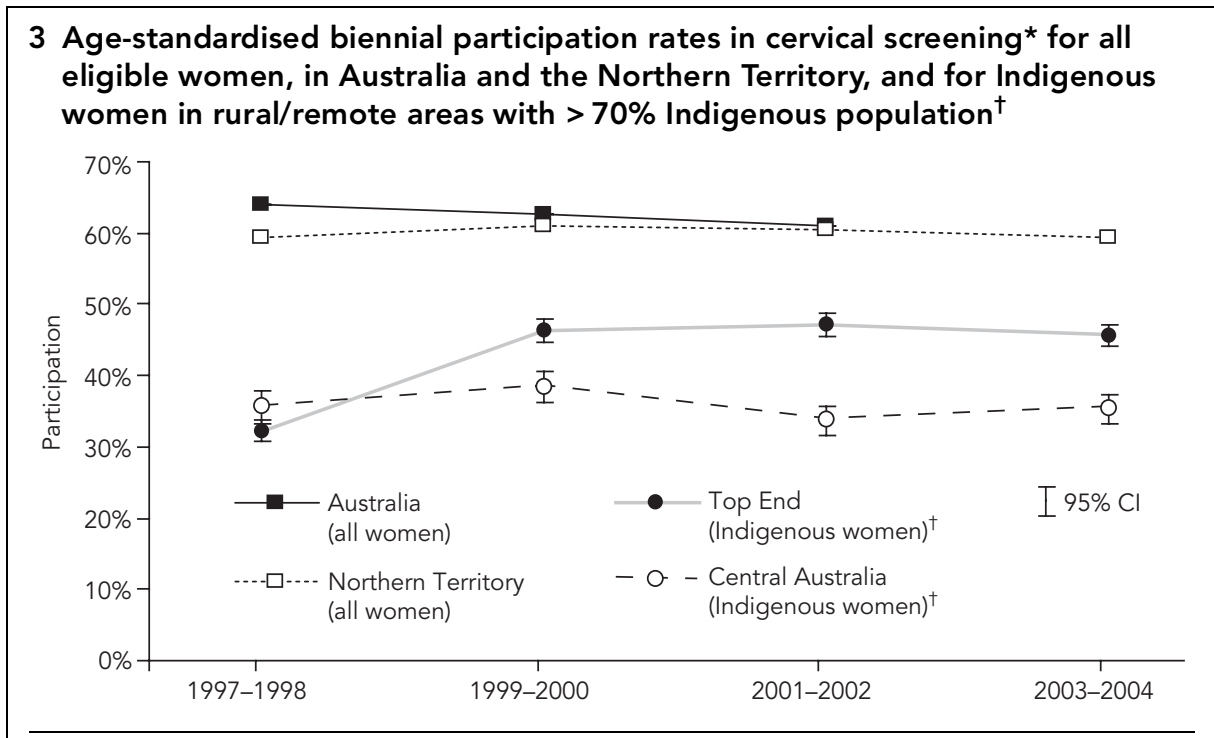

*Australian adjusted rates (1997-2000) are expressed as a percentage of the eligible female population (adjusted for the estimated proportion of women who have had a hysterectomy using National Health Service 1991 hysterectomy fractions) who have had at least one Pap smear and age-standardised to the 1991 Australian Standard population. ${ }^{8}$ All other adjusted rates are calculated using NHS 2001 hysterectomy fractions and the 2001 Australian Standard population age-adjusted to the age-distribution of the 2001 Australian population. † Areas where Indigenous women made up $>70 \%$ of the female population.
$2.7 \%$ ) and $3.2 \%$ lower (range, $1.7 \%-4.6 \%$ ), respectively. pation in these "> $70 \%$ Indigenous areas" has remained higher in the Top End than in Central Australia, where there has been no overall improvement (Box 3). Within Central Australia, trends varied between these rural/remote areas (Box 4): in Area $H$, rates increased in the last time period, but, in Area G, rates fell after 2000. Participation in Area I improved, but overall this area had the lowest participation. Notably, Area D in the Top End had participation rates that were higher than total NT and Australian rates from 1999. This area also had the highest proportion of Indigenous residents.

\section{Sensitivity analyses}

Non-Indigenous women comprised only $11.1 \%$ of the population in the nine rural/ remote areas studied. Varying the assumption of the rate of non-Indigenous participation made little difference to estimated Indigenous participation rates: if nonIndigenous participation was $51 \%$, the Indigenous participation rate would have been, on average, $1.1 \%$ higher (range, $0.3 \%-1.6 \%$ ) in areas with an Indigenous population greater than $90 \%$ and, on average, $3.0 \%$ higher (range 1.5\%-4.8\%) in areas with Indigenous populations between $70 \%$ and $89 \%$. If non-Indigenous participation was $71 \%$, Indigenous rates would have been, on average, $1.3 \%$ lower (range, $0.1 \%-$

\section{DISCUSSION}

Our study is the first to report longitudinal trends in cervical screening participation for Indigenous Australian women. An increase in participation rate was shown from 19971998 to 1999-2000, but no increase thereafter. Participation was very low in 19971998, at least for the 55\% of the NT Indigenous female population who lived in rural/ remote areas. However, from 1999-2000, there was a considerable increase in participation for Indigenous women in rural/ remote areas in the Top End, but little change for those in Central Australia. Nevertheless, except for one Top End rural/remote area (Area D), participation rates for Indigenous women remained lower than those in NT urban areas and in Australia overall. Two other studies in Queensland and New South Wales also reported estimated Indigenous participation rates that were lower than those of the respective state populations. ${ }^{13,14}$ The only other reports of Indigenous participation have been from single communities. ${ }^{15-20}$

Our study has some limitations. Screening participation rates could be calculated only after establishment of the NTPSR in 1996, while NT Indigenous cervical cancer incidence began to decline before 1997. The NTWCPP was established in 1994 and rolled out throughout the NT over the following 4-6 years through funded positions for women's health educators, provider education and public campaigns. ${ }^{7}$ Consequently, a substantial effect on participation would not be expected in the early years of the program. Nevertheless, just as the reduction in national cervical cancer incidence has been attributed in large part to the organised National Screening Program, ${ }^{1,3}$ it seems likely that the reductions in NT Indigenous cervical cancer incidence and mortality may be at least partly attributable to improved participation in screening achieved by the NTWCPP.

Deficiencies in data availability imposed two limitations. Firstly, the absence of data on Indigenous status in the NTPSR necessitated indirect estimation of Indigenous participation rates, limited to areas with predominantly Indigenous populations. Sensitivity analyses indicated that indirect estimates for these areas are reliable. However, if participation of non-Indigenous women was more than $10 \%$ below national rates, then participation rates of Indigenous 


\begin{tabular}{|c|c|c|c|c|c|c|c|c|c|}
\hline \multicolumn{10}{|c|}{$\begin{array}{l}4 \text { Estimated age-standardised biennial participation rates in cervical screening* for Indigenous women in rural/remote } \\
\text { areas with }>70 \% \text { Indigenous population }{ }^{\dagger}\end{array}$} \\
\hline \multirow{3}{*}{$\begin{array}{l}\text { Rural/ } \\
\text { remote } \\
\text { area }\end{array}$} & \multirow{3}{*}{$\begin{array}{l}\text { Indigenous/total } \\
\text { female population } \\
\text { in } 2001 \text { (\%) }\end{array}$} & \multicolumn{8}{|c|}{ Total number of women having Pap smears ${ }^{\ddagger}$ and estimated Indigenous participation rate $(95 \% \mathrm{Cl})$} \\
\hline & & \multicolumn{2}{|r|}{$1997-1998$} & \multicolumn{2}{|r|}{ 1999-2000 } & \multicolumn{2}{|r|}{$2001-2002$} & \multicolumn{2}{|r|}{$2003-2004$} \\
\hline & & No. ${ }^{\ddagger}$ & $\begin{array}{l}\text { Participation } \\
\text { rate (\%) }\end{array}$ & No..$^{\ddagger}$ & $\begin{array}{l}\text { Participation } \\
\text { rate }(\%)\end{array}$ & No. ${ }^{\ddagger}$ & $\begin{array}{l}\text { Participation } \\
\text { rate }(\%)\end{array}$ & No..$^{\ddagger}$ & $\begin{array}{l}\text { Participation } \\
\text { rate (\%) }\end{array}$ \\
\hline \multicolumn{10}{|l|}{ Top End } \\
\hline Area A & $1272 / 1494(85.1 \%)$ & 308 & $27.2(23.8-30.7)$ & 287 & $26.2(22.8-29.7)$ & 422 & $50.4(45.9-54.9)$ & 386 & $45.0(40.8-49.1)$ \\
\hline Area B & 2060/2239 (92.0\%) & 430 & $38.9(34.5-43.2)$ & 586 & $53.8(49.6-58.0)$ & 612 & $50.9(47.1-54.7)$ & 648 & $54.9(51.4-58.4)$ \\
\hline Area C & $1504 / 1853(81.2 \%)$ & 296 & $30.5(26.1-34.8)$ & 396 & $42.0(37.6-46.4)$ & 424 & $40.3(36.2-44.4)$ & 358 & $28.6(25.0-32.1)$ \\
\hline Area D & $1144 / 1213(94.3 \%)$ & 307 & $52.1(47.0-57.2)$ & 438 & 75.0 (70.8-79.2) & 456 & $72.6(68.8-76.3)$ & 422 & $69.4(65.6-73.2)$ \\
\hline Area E & $1144 / 1436(79.7 \%)$ & 284 & $28.9(24.5-33.2)$ & 342 & $41.4(36.5-46.3)$ & 351 & $40.3(35.8-44.8)$ & 304 & $31.2(27.0-35.3)$ \\
\hline Area F & $3444 / 3728$ (92.4\%) & 603 & 26.2 (23.9-28.5) & 856 & $42.2(39.5-45.0)$ & 852 & 38.7 (36.2-41.2) & 874 & $42.5(39.9-45.1)$ \\
\hline \multicolumn{10}{|c|}{ Central Australia } \\
\hline Area G & $2811 / 3066$ (91.7\%) & 692 & $47.2(44.0-50.3)$ & 722 & $46.1(43.1-49.1)$ & 661 & $36.8(34.0-39.6)$ & 698 & $38.8(36.1-41.6)$ \\
\hline Area $\mathrm{H}$ & $823 / 900(91.4 \%)$ & 170 & $28.3(23.4-33.3)$ & 165 & $31.8(27.0-36.7)$ & 164 & $31.2(26.0-36.4)$ & 201 & 44.9 (39.5-50.3) \\
\hline Area I & 1502/1733 (86.7\%) & 195 & $16.6(13.4-19.8)$ & 265 & $24.8(21.1-28.4)$ & 279 & $27.3(23.6-31.1)$ & 261 & $22.3(19.1-25.5)$ \\
\hline \multicolumn{10}{|c|}{ Northern Territory } \\
\hline Areas A to I & 15704/17662 (88.9\%) & 3285 & $33.9(32.6-35.2)$ & 4057 & $44.0(42.7-45.4)$ & 4221 & $42.7(41.4-43.9)$ & 4152 & $42.2(41.0-43.4)$ \\
\hline
\end{tabular}

women would be higher than estimated. Accurate identification of Indigenous women in the NTPSR would enable direct calculation of Indigenous participation rates for urban as well as remote areas. The NT is able to record very accurate data on Indigenous status in other health data collections ${ }^{21,22}$ and should be able to do the same for the NTPSR - either through direct data collection or through linkage with the Client Master Index of the NT public health system's Client Administration System.

The second data limitation arose as the NTPSR records only the most recent address for each woman. Those who migrate out of the NT remain on the register with their last NT address, unless the registry is notified. Participation rates were calculated assuming that women resided in that location for each biennial period, but it is conceivable that inmigration within the NT may have affected some regions more than others.

It is not known how many women chose to "opt off" the NTPSR, but this has been found elsewhere to cause only a small underestimation of participation rates for both Indigenous and non-Indigenous women. ${ }^{13}$ Applying the national hysterectomy fractions to the Indigenous population denominator may potentially overestimate Indigenous participation, as hysterectomies are less common in Indigenous than non-
Indigenous women. ${ }^{13,23}$ However, the effect is likely to be minimal, as the Indigenous population is relatively young, and hysterectomy fractions are small and vary little within younger groups. ${ }^{13}$

Despite these limitations, it is clear that Indigenous and non-Indigenous women living in rural/remote regions of the NT, especially in Central Australia, are not accessing cervical screening as frequently as women living in urban centres. This was not previously apparent to the NTWCPP as participation for the Apatula region (corresponding to the NT Alice Springs Rural Administrative Health District) had previously been estimated as higher than national rates: 62\% between July 1997 and June 19997,24 (compared with 42\% in 1997-1998 in our study). Previous estimates were based on incorrect automated coding of region of residence (as explained in the Methods section). These results have been communicated to staff to ensure that health promotion, education and clinical services are specifically targeted towards the areas involved.

In Top End regions, the NTWCPP has had a sustained positive effect on screening rates since 1999-2000. In Area D, Indigenous women have been able to access screening at a higher level than urban women, demonstrating that national levels of screening participation are attainable by Indigenous women living in remote areas. The factors responsible for this achievement need to be investigated and, where possible, adapted to achieve similar success elsewhere.

Increased screening participation may not be the only reason that cervical cancer incidence and mortality have fallen in NT Indigenous women. An essential component of screening is access to adequate follow-up and treatment. Initiatives such as the Gynaecology Outreach Service, which commenced in 1997, may also have played a part by improving access to follow-up and treatment after a screen-detected abnormality. ${ }^{25}$ This also warrants investigation.

We have, for the first time, estimated trends in cervical screening participation for most NT Indigenous women. The reduction in cervical cancer incidence and mortality in Indigenous women coincides with increased screening participation. The very high participation rates achieved in one area of the NT may have important lessons for remote areas throughout Australia; we have recommended to the NTWCPP that this be investigated, and the reasons for this success shared. Discussions about options for such an investigation and strategies to improve participation are underway. It is important that effective information systems are available to support evaluation of Indigenous 
health programs, so that public health practices such as screening can become more evidence-based. ${ }^{26}$

The NTPSR, in addition to its primary function of producing reminders for women to attend screening and follow-up, provides a useful resource for such evaluation. However, the full potential of the NTPSR to monitor the effectiveness of cervical cancer prevention programs will not be fully realised until it includes data on Indigenous status, retains data on previous place of residence, works with pathology laboratories to estimate the proportion of women who "opt-off" the register, and improves its capacity to provide information in a regular and timely manner.

Indigenous women need not experience any greater burden of cervical cancer morbidity and mortality than non-Indigenous women. Although the gap is closing in the NT, health service planners and providers must ensure this trend continues, by gathering and responding to the evidence.

\section{ACKNOWLEDGEMENTS}

Philippa Binns was funded by the Masters of Applied Epidemiology Program, Australian National University, through the Australian Department of Health and Ageing. John Condon was funded by a National Health and Medical Research Council public health capacity building grant (No. 236235). The NT Women's Cancer Prevention Program provided data for the study. We thank Chris Tyzack, Guillermo Enciso, Cynthia Croft, Vicki Krause, Scott Cameron, Frank Siciliano, Joan Cunningham and Craig Boutlis for their helpful advice and generous assistance.

\section{COMPETING INTERESTS}

None identified.

\section{AUTHOR DETAILS}

Philippa L Binns, FRACGP, MAppEpid, Master of Applied Epidemiology Scholar, ${ }^{1-3}$ currently, Medical Epidemiologist, South Eastern Sydney and Illawarra Area Health Service Public Health Unit, Wollongong, NSW

John R Condon, FAFPHM, PhD, Senior

Research Fellow ${ }^{3,4}$

1 National Centre for Epidemiology and

Population Health, Australian National

University, ACT.

2 Centre for Disease Control, Department of Health and Community Services, Darwin, NT.

3 Cooperative Research Centre for Aboriginal Health, Darwin, NT.

4 Menzies School of Health Research and

Institute of Advanced Studies, Charles Darwin

University, Darwin, NT.

Correspondence:

philippa.binns@sesiahs.health.nsw.gov.au

\section{REFERENCES}

1 Australian Institute of Health and Welfare and Australasian Association of Cancer Registries. Cancer in Australia 2001. Canberra: AlHW, 2004. (AlHW Cat. No. CAN 23; Cancer Series Report No. 28.)

2 Ferley J, Bray F, Pisani P, Parkin DM. GLOBOCAN 2002: cancer incidence, mortality and prevalence worldwide. International Agency for Research on Cancer. CancerBase No. 5, version 2.0. Lyon: IARCPress, 2004. http://wwwdep.iarc.fr/ (accessed Nov 2005).

3 National Cervical Screening Program. Screening to prevent cervical cancer: guidelines for the management of asymptomatic women with screen detected abnormalities. Canberra: National Health and Medical Research Council, 2005. http://www.nhmrc.gov.au/publications/_ files/wh39.pdf (accessed Nov 2005).

4 Condon JR, Armstrong BK, Barnes T, et al. Cancer incidence and survival for Indigenous Australians in the Northern Territory. Aust N Z J Public Health 2005; 29: 123-128.

5 Condon JR, Barnes T, Cunningham J, Armstrong BK. Long-term trends in cancer mortality for Indigenous Australians in the Northern Territory. Med J Aust 2004; 180: 504-507.

6 Australian Bureau of Statistics. Regional statistics, Northern Territory, 2005. Canberra: ABS, 2005. (ABS Cat. No. 1362.7. 2005.) http:// www.abs.gov.au/Ausstats/abs@.nsf/e8ae 5488b598839cca25682000131612/04c2cf10 fac92ff3ca256ae2007d1c83!OpenDocument (accessed Nov 2005).

7 Making a difference for Northern Territory women: six years on. NT Women's Cancer Prevention Program Report to June 11999. Darwin: Territory Health Services, Northern Territory Government, 2001.

8 Australian Institute of Health and Welfare. Cervical screening in Australia Series 1998-2003. Canberra: AlHW, 2002-2005. (AlHW Cat. Nos. CAN 11, CAN 19, CAN 22 and CAN 26.)

9 Northern Territory of Australia Public Health (Cervical Cytology Register) Regulations. 2005. http://notes.nt.gov.au/dcm/legislat/legislat.nsf/d989974724db65b1482561 cf0017cbd2/ 14763de5528db73c692570e5000acf22/\$FILE/ Repp023R9.pdf (accessed Sep 2006).

10 Edwards R. Australian standard geographical classification (ASGC) 2001. Canberra: Australian Bureau of Statistics, 2001. (ABS Cat. No. 1216.0.)

11 Australian Bureau of Statistics. Australian demographic statistics, September quarter 2002. Canberra: ABS, 2002. (ABS Cat. No. 3101.0.)

12 Australian Bureau of Statistics. 2001 National Health Survey: summary of results. Canberra: ABS, 2002. (ABS Cat. No. 4364.0.)

13 Coory MD, Fagan PS, Muller JM, Dunn NAM. Participation in cervical cancer screening by women in rural and remote Aboriginal and Torres Strait Islander communities in Queensland. Med J Aust 2002; 177: 544-547.

14 Wain G, Morrell S, Taylor R, et al. Variation in cervical cancer screening by region, socio-economic, migrant and indigenous status in women in New South Wales. Aust N Z J Obstet Gynaecol 2001; 41: 320-325.
15 Gilles MT, Crewe S, Granites IN, et al. A community-based cervical screening program in a remote Aboriginal community in the Northern Territory. Aust J Public Health 1995; 19: 477-481.

16 Hunt JM, Gless GL, Straton JA. Pap smear screening at an urban aboriginal health service: report of a practice audit and an evaluation of recruitment strategies. Aust N Z J Public Health 1998; 22: 720-725.

17 Mak D, Straton JA. Effects and sustainability of a cervical screening program in remote Aboriginal Australia. Aust N Z J Public Health 1997; 21: 67-70.

18 Mak DB, Straton JA. The Fitzroy Valley Pap Smear Register. Cervical screening in a population of Australian Aboriginal women. Med J Aust 1993; 158: 163-166.

19 Guest C, Mitchell H, Plant A. Cancer of the uterine cervix and screening of Aboriginal women. Aust N Z J Obstet Gynaecol 1990; 30: 243-247.

20 Couzos S, Wronski I, Murray R, et al. Augmentation of Pap smear screening of high risk aboriginal women. Use of a computerised process tool within the Broome Aboriginal Medical Service. Aust Fam Physician 1998; 27: 269-274.

21 Condon JR, Williams DJ, Pearce MC, et al. Northern Territory hospital morbidity dataset: validation of demographic data 1997. Darwin: Territory Health Services, 1998.

22 Condon JR, Zhao Y, Armstrong BK, et al. Northern Territory Cancer Register Data Quality 1981-2001. Darwin: Department of Health and Community Services, 2004.

23 Yusuf F, Siedlecky S. Hysterectomy and endometrial ablation in New South Wales, 1981 to 1994-1995. Aust N Z J Obstet Gynaecol 1997; 37: 210-216.

24 Volkmar-Campbell JV, Kurnoth P. Well women making a difference: evaluation report and program guide. Darwin: Women's Cancer Prevention Program, Department of Health and Community Services, Northern Territory Government, 2000.

25 Gruen RL, Bailie RS, d'Abbs PH, et al. Improving access to specialist care for remote Aboriginal communities: evaluation of a specialist outreach service. Med J Aust 2001; 174: 507511.

26 Bailie R, Sibthorpe B, Anderson I, et al. Data for diagnosis, monitoring and treatment in indigenous health: the case of cervical cancer. Aust $N$ Z J Public Health 1998; 22 (3 Suppl): 303-306.

(Received 6 Mar 2006, accepted 27 Jun 2006) 